\title{
Shaking-Swing Coupled Vibration Analysis of a Laminar Composite Rotating Blade by the Finite Element Method
}

\section{Yao and C. Zheng}

School of Physics and Electromechanical Engineering, Shaoguan University, Shaoguan, China

yuripean@163.com

For studying the vibration characteristics of a laminar composite rotating blade, the spin softening effect calculated by the finite element method (FEM) was incorporated with the prestress effect to analyze shaking, swing, torsion, and coupled vibrations. The mathematical formula was derived. The study shows that the centrifugal force exerts influence on the difference in vibration frequencies. The laminar composite can reduce an influence of the spin softening on the first swing vibration frequency because of its structure and smaller density. With the variation of rotating velocity, the blade spin softening can lead to the coupled first shaking and first swing vibrations. In the coupled vibrations, swing is contained in the shaking mode and shaking is also contained in the swing one, which is the reason of major blade damages. The results confirm the complexity of the dynamic characteristics of the laminar composite rotating blade. This method is also well applicable to the dynamic design of such blades.

Keywords: composite blade, spin softening, prestress, swing, coupled vibration.

Introduction. Shaking-swing coupled vibration of a rotating blade can occur in many engineering structures such as aircraft propellers, helicopters and wind turbine rotors. These structures are usually made of composite materials. The analysis model of a rotating laminated composite blade is involved with the effects of shear deformation, in-plane and rotary inertia and deformation. In recent years, the field of dynamic analysis of rotating blades is continually, steadily expanding. Various theories, such as classical, shear deformation, 3D, nonlinear and others, were proposed and proceeded with the dynamic analysis of composite shells [1]. The large amplitude free flexural vibration behavior of symmetrically laminated composite skew plates is investigated using the finite element method (FEM) and the variation of nonlinear frequency ratios with amplitudes is brought out considering various parameters such as skew angle, fiber orientation and boundary condition $[2,3]$. The blades are modeled as discrete multi- degree-of-freedom system using the finite element software code ANSYS allowing the free vibration characteristics of the rotating blades to be determined by analytical formulation [4]. The micromechanics bridging model constitutive theory of composite materials was incorporated with finite element software ABAQUS through a user subroutine UGENS to analyze the progressive failure process and ultimate strength of a composite wind turbine blade, which has a complicated three-dimensional geometry [5]. A rotor manipulation mechanism for micro unmanned helicopter utilizing the inertia and the elasticity of the rotor is introduced, and the natural frequencies, mode shapes of the blade for the helicopter are studied by using beam characteristic orthogonal polynomials by the Rayleigh-Ritz method and the variation of natural frequencies with the speed of rotation and the mode shapes at different rotational speeds are plotted [6]. The spin softening effect of a metal blade usually causes the first swing vibration reduced substantially [7]. The effect is lower by using the laminated composite blade in this paper. The study results on rotor dynamics provide a necessary foundation for further study on the coupled vibration of a rotating laminated composite blade [8-15]. 
Vibration Equation. FEM describes the motion of a dynamic blade with the equation

$$
[M]\{\ddot{u}\}+([G]+[C])\{\dot{u}\}+[K]\{u\}=\{F\},
$$

where $[M]=\sum_{i}^{n}\left[M_{e}\right]$ is the global mass matrix, $[G]=\sum_{i}^{n}\left[G_{e}\right]$ is the global Coriolis matrix, $[C]$ is the global damping matrix, $[K]$ is the global stiffness matrix, $\{F\}$ is the load vector, $\{u\}$, $\{\dot{u}\}$, and $\{\ddot{u}\}$ are the displacement, velocity, and acceleration vector, respectively,

$$
\begin{gathered}
{\left[M_{e}\right]=\int_{V}[N]^{T}[N] \rho d v, \quad\left[G_{e}\right]=\int_{V}[N]^{T}[\Omega][N] \rho d v,} \\
{[\Omega]=\left[\begin{array}{ccc}
0 & -\omega_{z} & \omega_{y} \\
\omega_{z} & 0 & -\omega_{x} \\
-\omega_{y} & \omega_{x} & 0
\end{array}\right],}
\end{gathered}
$$

where $\left[M_{e}\right]$ is the element mass matrix, $[\Omega]$ is the angular velocity matrix, $\left[G_{e}\right]$ is the element Coriolis matrix, $[N]$ is the shape function matrix, $v$ is the element volume, and $\rho$ is the density.

Vibration Equation Based on Prestress. Structures become stiffer in rotation, which lead to the introduction of the global prestress stiffening matrix $([\bar{S}])$. The global prestress stiffening matrix accounts for this effect by adding stiffness to global stiffness matrix $([K])$ in a dynamic linear problem

$$
[M]\{\ddot{u}\}+([G]+[C])\{\dot{u}\}+([K]+[\bar{S}])\{u\}=\{F\} .
$$

An element prestress stiffening $\left(\left[S_{e}\right]\right)$ is

$$
\begin{array}{ccc}
{\left[S_{e}\right]=\left[\begin{array}{ccc}
{\left[S_{0}\right]} & {[0]} & {[0]} \\
{[0]} & {\left[S_{0}\right]} & {[0]} \\
{[0]} & {[0]} & {\left[S_{0}\right]}
\end{array}\right], \quad\left[S_{0}\right]=\int_{v}\left[S_{g}\right]^{T}\left[S_{m}\right]\left[S_{g}\right] d v,} \\
{\left[S_{m}\right]=\left[\begin{array}{ccc}
\sigma_{x} & \sigma_{x y} & \sigma_{x z} \\
\sigma_{x y} & \sigma_{y} & \sigma_{y z} \\
\sigma_{x z} & \sigma_{y z} & \sigma_{z}
\end{array}\right],} & {\left[S_{g}\right]=\left[\begin{array}{cccc}
\frac{\partial N_{1}}{\partial x} & \frac{\partial N_{2}}{\partial x} & \cdots & \frac{\partial N_{8}}{\partial x} \\
\frac{\partial N_{1}}{\partial y} & \frac{\partial N_{2}}{\partial y} & \cdots & \frac{\partial N_{8}}{\partial y} \\
\frac{\partial N_{1}}{\partial z} & \frac{\partial N_{2}}{\partial z} & \cdots & \frac{\partial N_{8}}{\partial z}
\end{array}\right] .}
\end{array}
$$

Vibration Equation Based on Spin Softening. The global stiffness is reduced, taking the effect of spin softening into account. According to Newton's second law, equilibrium for the system can be written as (Fig. 1)

$$
K u=\omega_{z}^{2} M(r+u),
$$

where $\omega_{z}$ is the angular velocity around the $z$ axis.

Re-ordering the terms

$$
\left(K-\omega_{z}^{2} M\right) u=\omega_{z}^{2} M r,
$$




$$
\bar{K}=K-\omega_{z}^{2} M
$$

Stiffness $(\bar{K})$ is smaller than $K$, namely spin softening.

In the global FE-formulation, the dynamic equation accounting for spin softening is written, according to the discussion above, as

$$
[M]\{\ddot{u}\}+([G]+[C])\{\dot{u}\}+\left([K]+[\bar{S}]-\omega_{z}^{2}[M]\right)\{u\}=\{F\},
$$

where the stiffness matrix $\left(-\omega_{z}^{2}[M]\right)$ corresponds to the spin softening, i.e., it reduces the total stiffness. By setting the effects of prestress and spin softening, Eq. (7) can adequately provide the dynamic analysis of the rotating laminated composite blade by using the ANSYS 10.0.

Numerical Results. The wind turbine blade length is $4.42 \mathrm{~m}$, rated output power $20 \mathrm{~kW}$, blade airfoil SG6050, rated speed $78 \mathrm{rpm}$, the maximum speed $105 \mathrm{rpm}$, rated wind speed $11 \mathrm{~m} / \mathrm{s}$, starting wind speed $4-4.5 \mathrm{~m} / \mathrm{s}$, wind speed range 4-20 m/s, the maximum wind resistance $50 \mathrm{~m} / \mathrm{s}$ [5]. The blade shape parameters are listed in Table 1, while the airfoil section is depicted in Fig. 2.

$\mathrm{T}$ a b 1 e 1

Geometric Data of a $20 \mathrm{~kW}$ Turbine Blade

\begin{tabular}{||c|c|c|c|c|c|c|c||}
\hline Section & $\begin{array}{c}\text { Radius } \\
(\mathrm{m})\end{array}$ & $\begin{array}{c}\text { Chord } \\
\text { length }(\mathrm{m})\end{array}$ & $\begin{array}{c}\text { Twist } \\
\text { angle (deg) }\end{array}$ & Section & $\begin{array}{c}\text { Radius } \\
(\mathrm{m})\end{array}$ & $\begin{array}{c}\text { Chord } \\
\text { length }(\mathrm{m})\end{array}$ & $\begin{array}{c}\text { Twist } \\
\text { angle (deg) }\end{array}$ \\
\hline 1 & 0.244 & 0.31 & 25.4 & 10 & 2.000 & 0.370 & 5.60 \\
2 & 0.300 & 0.34 & 25.8 & 11 & 2.500 & 0.330 & 2.60 \\
3 & 0.400 & 0.38 & 26.3 & 12 & 3.000 & 0.280 & 0.76 \\
4 & 0.500 & 0.42 & 26.8 & 13 & 3.300 & 0.260 & 0 \\
5 & 0.632 & 0.48 & 27.4 & 14 & 3.500 & 0.240 & -0.45 \\
6 & 0.800 & 0.46 & 23.0 & 15 & 4.000 & 0.200 & -1.20 \\
7 & 1.000 & 0.45 & 17.5 & 16 & 4.368 & 0.170 & -1.78 \\
8 & 1.100 & 0.44 & 15.0 & 17 & 4.420 & 0.168 & -2.00 \\
9 & 1.500 & 0.41 & 10.0 & & & & \\
\hline
\end{tabular}

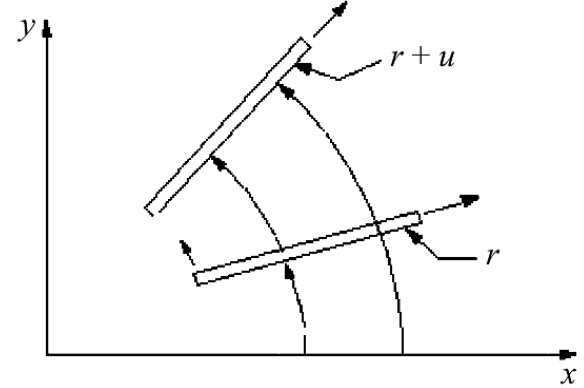

Fig. 1. The rotating bladeaxial displacement.

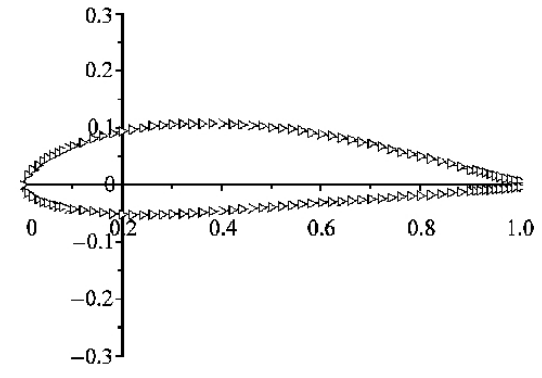

Fig. 2. SG6050 airfoil section.

The material selected for the blade is a carbon fiber-reinforced epoxy composite. The layout schedule is given in Table 2 .

The $0^{\circ}$ layer is subjected to the axial deformation, $\pm 45^{\circ}$ layer to shear and torsion deformation, while $90^{\circ}$ layer increases the blade stiffness. The mechanical properties of the material under study are tabulated in Table 3. 
$\mathrm{T}$ a b 1 e 2

\section{Layout Schedule}

\begin{tabular}{|c|c|c||}
\hline Structure & Fiber layout & Thickness $(\mathrm{mm})$ \\
\hline Vertical rib & {$\left[0^{\circ} \pm 45^{\circ} / 0^{\circ} / 90^{\circ} / 0^{\circ}\right]_{S}$} & 10.0 \\
\hline Skin & {$\left[0^{\circ} \pm 45^{\circ} / 0^{\circ} / 90^{\circ} / 0^{\circ}\right]_{S}$} & 3.6 \\
\hline
\end{tabular}

$\mathrm{T}$ a b 1 e 3

Mechanical Properties of Materials [5]

\begin{tabular}{|c|c|c|c|c||}
\hline \hline$E_{11}, \mathrm{GPa}$ & $E_{22}, \mathrm{GPa}$ & Poisson's ratio & $G_{12}, \mathrm{GPa}$ & $\rho, \mathrm{kg} / \mathrm{m}^{3}$ \\
\hline 94.46 & 6.981 & 0.284 & 2.945 & 1800 \\
\hline
\end{tabular}

According to the stress characteristics of the section, the section $(0.15-0.5) C$ ( $C$ is section chord) is furnished with reinforcing ribs, in order to improve the overall stiffness of the blade, increase the bearing capacity and prevent the local instability. The blade structure adopts the hollow thin-walled structure (Fig. 3).

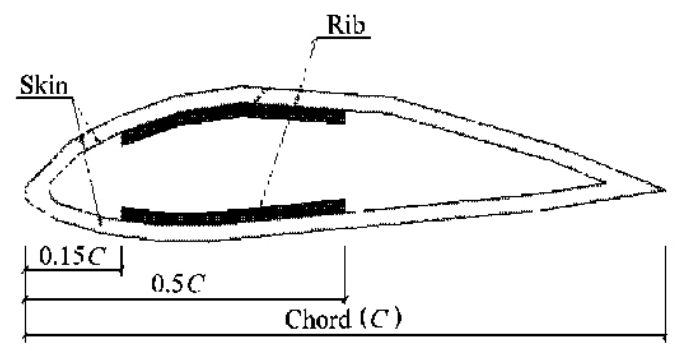

Fig. 3. SG6050 internal structure.

Vibration Analysis. The ANSYS meshing tools do not have specific requirements. Mesh of higher density, higher accuracy, but the amount of calculation is large, time is too long. The blade is divided into 4466 nodes and 4050 elements by using the Solid46 element model. The root is rigid, and the root nodes of the six degrees of freedom are fixed. The blade is simplified as the cantilever beam model. The vibration model of the blade is calculated based on different rotating speed, and the results are shown in Tables 4 and 5 .

T a b 1 e 4

Vibration Frequencies $\omega$ of the Blade Based on Spin Softening ( $\omega$ in $\mathrm{rad} / \mathrm{s}$ )

\begin{tabular}{||c|c|c|c|c|c|c||}
\hline Order & $\begin{array}{c}\text { Vibration } \\
\text { mode }\end{array}$ & $n=0$ & $\begin{array}{c}\text { Vibration } \\
\text { mode }\end{array}$ & $n=200 \mathrm{rpm}$ & $\begin{array}{c}\text { Vibration } \\
\text { mode }\end{array}$ & $n=400 \mathrm{rpm}$ \\
\hline 1 & Shaking 1 & 10.55 & Shaking & 19.15 & Shaking & 26.94 \\
3 & Swing 1 & 27.00 & Swing 1 & 33.54 & Swing 1 & 43.71 \\
4 & Shaking 2 & 57.53 & Shaking & 63.62 & Shaking & 80.51 \\
5 & Swing 2 & 63.05 & Swing 2 & 78.69 & Swing 2 & 96.15 \\
6 & Shaking 3 & 82.33 & Shaking & 95.96 & Shaking & 125.66 \\
7 & Shaking 4 & 153.92 & Shaking & 165.60 & Shaking & 184.19 \\
8 & Swing 3 & 180.17 & Swing 3 & 189.53 & Swing 3 & 226.90 \\
9 & Thaking 5 & 262.76 & Shaking & 281.28 & Torsion 1 & 314.75 \\
\hline
\end{tabular}


$\mathrm{T}$ a $\mathrm{b} 1$ e 5

Vibration Frequency $\omega$ of the Blade Based on Spin Softening $(n=1291 \mathrm{rpm}, \omega$ in $\mathrm{rad} / \mathrm{s})$

\begin{tabular}{|c|c|c|c|c|}
\hline Order & Vibration mode & Solid models & Shell models & Error comparison (\%) \\
\hline 1 & Shaking-swing & 135.15 & 129.62 & 4.1 \\
& coupling vibration & & & \\
2 & Shaking 2 & 226.83 & 218.67 & 3.6 \\
3 & Swing 2 & 250.64 & 240.65 & 4.0 \\
4 & Torsion 1 & 399.41 & 423.59 & -6.1 \\
\hline
\end{tabular}

As is seen from Table 4, frequencies increase with the speed, while low frequencies manifest a steeper increase.

The shaking-swing coupled vibration is between the first swing (Fig. 4) and the first shaking (Fig. 5) coupled vibration at $n=1291 \mathrm{rpm}$, which is the critical speed of the rotating laminated composite blade (Table 5).The accuracy of the solid model and the solution techniques have been demonstrated by comparison with Shell181 element model through the uses of the ANSYS finite element code, and the results of error $\leq \pm 6.1 \%$. The spin softening effect is relatively reduced at the first frequency swing. Insofar as the speed of the wind turbine blade is low, the shaking-swing coupled vibration does not usually happen, but for the helicopter blades the coupled vibration will occur inevitably.

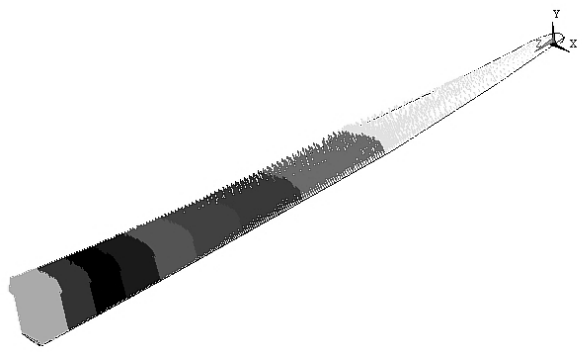

Fig. 4. The first shaking.

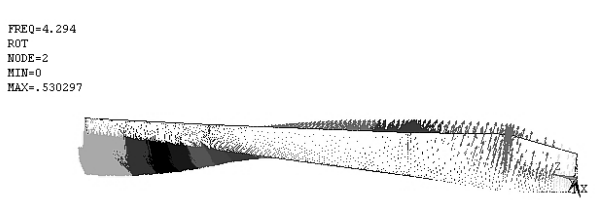

Fig. 5. The first swing.

Conclusions. Taking account of the effects of stress stiffening and spin softening, the shaking, swing, torsion vibration of the rotating laminated composite blade are calculated by ANSYS 10.0. It shows that the blade dynamic performance is poor, the first skating vibration and the first swing vibration frequency is small, susceptible to resonance and unstable. The use of the composite structure can reduce the influence of the spin softening on the first swing vibration frequency because of its structure design and lighter density.

With the variation of rotating velocity, both the shaking and swing vibration frequencies change with the different value of the increase. The spin softening effect reduced relatively on the first frequency swing. When the rotating velocity is close to $1291 \mathrm{rpm}$, it is easily induced by the coupled vibration between the first swing and the first shaking, whereas the shaking-swing coupled vibration is more destructive.

Acknowledgments. The authors are in debt to Prof. J. Chen, Prof. L. Q. Chen, Dr. T. Jia, and Dr. W. H. Huang for their fruitful discussions. The work was supported by the Natural Science Foundation of China under Grant No. 11172181, the Natural Science Foundation of Guangdong Province of China under Grant No. 10151200501000008, the Educational Foundation of Scientific and Technical Innovation of Guangdong Province of China under Grant No. 2013KJCX0167, and the Scientific Research Foundation of Key Discipline of Guangdong Province of China. 
1. S. M. Qatu, R. W. Sullivan, and W. C. Wang, "Recent research advances on the dynamic analysis of composite shells: 2000-2009," Compos. Struct., 93, No. 1, 14-31 (2010).

2. M. K. Singha and R. Daripa, "Nonlinear vibration of symmetrically laminated composite skew plates by finite element method," Int. J. Non-Linear Mech., 42, No. 9, 1144-1152 (2007).

3. M. K. Singha and M. Ganapathi, "Large amplitude free flexural vibrations of laminated composite skew plates," Int. J. Non-Linear Mech., 39, No. 10, 1709-1720 (2004).

4. P. J. Murtagh, B. Basu, and B. M. Broderick, "Mode acceleration approach for rotating wind turbine blades," Proc. Inst. Mech. Eng., Part K, J. Multi-Body Dynamics, 218, No. 3, 159-167 (2004).

5. C. L. Zhang, Z. M. Huang, and G. H. Dong, "Finite element ultimate analysis and design of composite wind turbine blade based on non-linear constitutive relationship," Acta Mater. Compos. Sinica, 24, No. 2, 174-182 (2007).

6. J. G. Lu, J. D. Wang, and D. R. Chen, "Transverse vibration of the blade for unmanned micro helicopter using Rayleigh-Ritz method," J. Univ. Sci. Technol. Beijing, 10, No. 6, 40-43 (2003).

7. X. S. Yao, "Study on dynamics of wind turbine blade based on spin softening," $J$. Chin. Soc. Power Eng., 31, No. 3, 209-213 (2011).

8. Y. Narita and J. M. Hodgkinson, "Layerwise optimization for maximising the fundamental frequencies of point-supported rectangular laminated composite plates," Compos. Struct., 69, No. 2, 127-135 (2005).

9. D. Y. Liu and Q. J. Meng, "Blade vibration characteristics calculation by using 3D incompatible finite element," Power Eng., 19, No. 4, 293-296 (1999).

10. O. I. Crabtree, S. D. Mesarovic, R. F. Richards, et al., "Nonlinear vibrations of a pre-stressed laminated thin plate," Mech. Sci., 48, No. 4, 451-459 (2006).

11. V. I. Gulyaev and S. N. Khudolii, "Vibrations of curved and twisted blades during complex rotation," Int. Appl. Mech., 41, No. 4, 449-454 (2005).

12. V. I. Gulyaev, P. Z. Lugovoi, and I. L. Solov'ev, "Elastic vibrations of a singlesupport thin-walled rotor (compound shell) during complex rotation," Int. Appl. Mech., 39, No. 8, 969-975 (2003).

13. Z. L. Xu, X. Y. Li, J. P. Park, and S. J. Ryu, "Effect of Coriolis acceleration on dynamic characteristics of high speed spinning steam turbine blades," J. Xian Jiaotong Univ., 37, No. 9, 894-897 (2003).

14. J. W. Xu, R. Tian, Z. Y. Gao, et al., "Study on structure's dynamic characteristic of the horizontal axis wind turbine," Acta Energy Solar Sinica, 28, No. 8, 834-838 (2007).

15. N. S. Bao, R. J. Cao, and Z. Q. Ye, "Structural vibration analysis for wind turbine blades using finite element method," Acta Energy Solar Sinica, 21, No. 1, 77-81 (2000). 